DOI: $10.17805 /$ zpu.2016.4.3

\title{
Общество потребления и ценности российской цивилизации
}

\author{
А. В. КОСТИНА \\ (МОСКОВСКИЙ ГУМАНИТАРНЫЙ УНИВЕРСИТЕТ)
}

Одним из понятий, введенных в практику достаточно давно, но остающихся операциональными, хотя и подвергающимися переосмыслению по настоящее время, является понятие «общество потребления». Еще три десятилетия назад этот термин воспринимался как атрибутивный исключительно западному обществу и наделялся негативными значениями. В статье анализируются особенности ценностной системы западного общества потребления и степень ее соответствия экономической системе Евроатлантической цивилизации. Сегодня очевидно, что общество потребления - явление достаточно универсальное, оно возникает там и тогда, где формируется рыночная экономика, становится устойчивым товарное изобилие, появляется потребность - для поддержания темпов производства товаров и услуг - в расширенном их потреблении, для чего посредством рекламы и СМИ формируется новый тип индивида - человек потребляющий.

Несмотря на то что общество потребления в большей степени было характерно для развитых экономик западных стран, в СССР его развитие осуществлялось в тот же послевоенный период достаточно высокими темпами. Сегодня ситуация в экономике России совершенно иная. Товарное изобилие и отсутствие дефицита в полной мере коррелируют с целенаправленной деятельностью СМИ по формированию установок на расширенное потребление. Система кредитования, общественное мнение, реклама целенаправленно формируют у россиян ценность потребления. Однако социокультурная система России находится в неполном взаимодействии, а подчас и противоречит принципам конкуренции.

Делается вывод о том, что основной целью государства должно быть формирование активной и творческой личности, а не человека-потребителя.

Ключевые слова: ценности; общество потребления; Россия; российская цивилизация; российские ценности; потребительское общество; западная цивилизация; западные ценности; свободная конкуренция

\section{ВВЕАЕНИЕ}

Понятие «общество потребления» является одним из базовых в социальной философии и восходит к идее К. Маркса о товарном фетишизме. В научную практику оно было введено Э. Фроммом и учеными Франкфуртской школы социальных исследований, но прочно вошло в социально-философский словарь после появления в 1970 г. книги Ж. Бодрийара «Общество потребления. Его мифы и структуры» (Baudrillard, 1998). Несмотря на скорее социально-политическое, чем научное «звучание» этого термина, он оказался настолько операциональным, что был быстро принят в качестве системообразующего в трудах социальных философов, отражая экономические и культурологические аспекты общественного развития.

Цель статьи - определить характер влияния общества потребления на ценностное содержание современной российской культуры, выявив трансформации современного российского общества, его экономики и социальной жизни в соответствии с распространением потребительских ценностей.

\section{РАЗВИТИЕ АИЧНОСТИ И ФОРМИРОВАНИЕ ПОТРЕБИТЕАЬСКОГО СОЗНАНИЯ:}

\section{АИАЕММА СОВРЕМЕННОГО «ОБЩЕСТВА ПОТРЕБАЕНИЯ»}

Английский термин consumer society ('потребительское общество') означает ту социальную систему, которая сложилась в странах Европейского и Североатлантиче- 
ского регионов в 1950-1970-е годы - в период их активного экономического и технологического развития, сопровождающегося не только значительным ростом доходов населения, но - что особенно важно - и весьма позитивными социальными преобразованиями. Именно в это время формируется и становится доминирующим средний класс как ядро социальной структуры, увеличивается объем индивидуального свободного времени, в обществе увеличивается дифференциация и растет число малых социальных групп, образуемых на основе общности интересов индивидов и их увлечений. В это время получают широкое распространение идеи постиндустриального и информационного общества, основанного на интеллектуальном труде, что отражает не только растущую роль в обществе коммуникационных технологий, но и компьютеризацию всех технологических процессов, а также формирование глобальных сетевых коммуникаций и - соответственно - глобального общества.

Безусловно значимая идея социального государства становится основой реальных политических решений относительно перераспределения материальных и общественных благ (а именно заработной платы, страховой системы, образования, медицины, пенсионного обеспечения и т. п.) в пользу широких социальных слоев, что собственно и приводит к формированию среднего класса, обеспеченного материальными благами в значительном объеме (Куренной, 2015: Электронный ресурс).

Одновременно получают распространение и те тенденции, которые сначала воспринимаются как временный «побочный продукт» развития среднего класса. Речь идет о присущем этому социальному слою расширенном массовом потреблении материальных благ и изменении структуры самого потребления, а также трансформации ценностной системы и формировании, а затем - и прочном усвоении досуговых ценностей (Софронов-Антомони, 2002).

Очевидно, что потребности любого общества ограничены определенными параметрами - и не важно, каково их количественное выражение, важно то, что любые потребности имеют пределы. В этой ситуации - для того, чтобы раздвинуть рамки этих пределов и расширить объем потребностей, - оказывается важнейшей роль СМИ. Сначала они формируют человека как потребителя, для которого наилучший и наиболее приемлемый с социальной точки зрения отдых - это досуг в торговом центре. А затем СМИ начинают формировать в обществе и новые потребности. Товары отчасти утрачивают свою потребительскую ценность, которая замещается их символической значимостью, само же потребление освобождается от его привычного значения как «процесса удовлетворения потребностей», наоборот - сам процесс производства и потребления активно формирует потребности (Рапай, 2008).

Не умаляя тех общественных ценностей, свобод и гарантий, которые формируются и обеспечиваются государством в западном обществе в это время - а именно оно и становится основанием для построения всех социально-философских моделей «постиндустриального», «информационного», «постбуржуазного», «посткапиталистического», «технотронного» и даже «активного» и «хорошего» общества, - отметим и другую их составляющую - потребительский бум. Возможно, немаловажной экономической причиной этих социальных преобразований стал именно стремительный технологический и промышленный рост - в первую очередь, товаров массового потребления, автомобилей, электробытовых приборов, разнообразных услуг, индустрии массовой культуры. Колоссальные объемы производства индустрии потребления требовали сбыта, для чего была сформирована платежеспособная масса в виде среднего класса, стимулируемая к потреблению и поддерживаемая в этой ее устремленности различ- 
ными финансовыми организациями через систему кредитования. Такая целенаправленная политика привела в западных странах за четыре десятилетия - с 1960-х по 2000-е годы - к увеличению расходов населения на потребительские нужды в 5 раз.

Что же происходит в обществе потребления? Почему существенное увеличение объема свободного времени у представителя этой общественной системы не приводит, вопреки прогнозам К. Маркса, к саморазвитию, раскрытию творческого потенциала, духовному росту человека? Почему свободное время, которое представителями Франкфуртской школы воспринималось как прибежище от принуждения, уводящее человека от ритма конвейера или движения в офисе, расходуется для потребления и само потребляется? Почему постоянные споры мыслителей о влиянии свободного времени на формирование личности, открытые еще Паскалем и Монтенем, первый из которых считал его самоубийством, второй - спасением, постоянно воспроизводятся? Кто прав? Паскаль, говоривший, что вернейший способ сделать человека несчастным - отнять у него заботы, «и он начнет думать, что он такое, откуда пришел, куда идет, - вот почему его необходимо с головой окунуть в дела, отвратив от мыслей» и придумать для него множество важных занятий, или Монтень, считавший стремление к все большему досугу средством самосохранения человека, и так как человеческие запросы и потребности (в том числе в развлечении) изменить нельзя, то их следует как можно лучше удовлетворять (цит. по: Аарошфуко, 1974: 143-144)? Кто был ближе к истине? Ж.-Ж. Руссо, считавший главной целью культуры в отношении человека - достижение его счастья, или И. Кант, убежденный в том, что культура предназначена для того, чтобы сформировать человека нравственного?

Вопрос о предназначении человека был характерен для эпохи Просвещения, он занимал и Й. Гердера, который, возможно, оказался прозорлив в том, что человеческая природа, несмотря на развитие цивилизации, остается неизменной, человек не становится в истории ни счастливее, ни нравственнее. При этом, подчеркнем это, в намеренном пессимизме автора упрекнуть трудно, как яркий представитель Просвещения, он оставался на позициях эволюционизма и мыслил категориями прогресса. И тем не менее, существо человека Гердер оценивал достаточно критично, допуская мысль о его несовершенстве, которое невозможно преодолеть посредством его развития.

Очевидно, для того чтобы человек в индивидуальном порядке реализовал гуманистический идеал, необходима его глубокая, осознанная, целенаправленная внутренняя духовная работа. Аля того же, чтобы гуманистический идеал был реализован в обществе в целом, кроме индивидуальной работы, необходимо продуманное, целенаправленное его формирование самим государством - через институты образования, СМИ, продукцию массовой культуры. Однако такой человек не очень «удобен» государству, он критичен, образован, социально активен, к тому же он очень плохой потребитель: как правило, богатая духовная жизнь не сопрягается с бездумным наслаждением от процесса потребления.

Но такой человек остается в определенном смысле «идеальной конструкцией», этому идеалу в реальной жизни в состоянии соответствовать достаточно небольшое число людей. В своей же массе индивид в массовом обществе не обладает ярко выраженным индивидуализированным началом и в своих жизненных стратегиях ориентируется не на развитие, а на потребление, реализуя через него стремление маркировать свою индивидуальность. Эту потребность в самопрезентации через обладание вещами определенного статуса поддерживает большинство институтов и механизмов «общество потребления», при этом идеал социального государства достаточно быстро 
утрачивает свои лучшие черты. Потребление постепенно становится потребностью, определяя все стратегии человеческой жизнедеятельности, наиболее же значительной ценностью становится само расширенное потребление.

Характерно, что через потребление определяются взаимоотношения и стран в глобальном сообществе - те из них, которые приобщены к мировым брендам, оказываются включенными в мировое глобальное пространство, не приобщенные же к ним автоматически исключаются из глобального сообщества (Стивенсон, 2002: 7). Примерно такой же процесс оказался связанным с санкциями западных стран, введенными ими против России. Экономически санкции не сильно повлияли на российскую экономику, ущерб выступил, скорее, как символический.

Безусловное доминирование в современном западном обществе потребительских ценностей актуализирует вопрос о причинах их столь прочного укоренения. ПреАставляется, что для Евроатлантической цивилизации они имманентны, более того, сама экономическая успешность в значительной степени обусловлена ее ценностным содержанием, а именно тем «духом капитализма», о котором писал еще М. Вебер. Системообразующим понятием в системе ценностей западного общества является понятие рационализма, который, как ценность, в значительной степени присущ европейскому сознанию. В свою очередь, он порождает установку на принятие ценностей инструментализма, операционализма, прагматизма, позитивизма, а также неои постпозитивизма. Европейскому сознанию присуще восприятие разума в качестве основы рациональной деятельности как стратегии и тактики, служащей реализации достижения успеха и признания. Отсюда - опора на ценности индивидуальности, социальной успешности, соответствия букве закона, активности, ориентации на монетарные ценности (Каган, 1997: 147), а также - оптимизма и благополучия. Эти ценностные основания в полной мере согласуются с основными параметрами общества потребления. Социальная успешность и финансовое благополучие являются не просто благом или одной из базовых потребностей человека, но наделяются сакральным значением как свидетельство правильности его жизненного пути, его стратегии, его взаимоотношения с миром.

\section{ОБЩЕСТВЕННОЕ БААГО УS АИЧНОЕ БААГОСОСТОЯНИЕ: \\ АИАЕММА СОВРЕМЕННОЙ РОССИЙСКОЙ КУАЬТУРЫ}

Насколько эти ценности согласуются с установками общества потребления в иных странах, с иными культурными кодами? Аля ответа на этот вопрос необходимо определить, в каких государствах общество потребления существует как такая же структура во всей полноте своих проявлений и функций, как это присуще Евроатлантической цивилизации. Несмотря на то что постиндустриальное общество уже сложилось как завершенная структура во многих странах Азии и Ближнего Востока, а его системные свойства присущи развитию и современной России, об «обществе потребления» в его классических проявлениях во многих странах говорить затруднительно. Влиянию потребительского бума сопротивляется (по крайней мере, пока) китайская культура с ее установками на сдержанность и умеренность, индийская культура, не уделяющая материальным ценностям большого значения. Потребительский культурный код является принципиально иным и по сравнению с тем, который лежит в основаниях Российской цивилизации, которая зиждется на ином фундаменте.

В основе российского цивилизационного кода доминирует установка не на всеобщее и рационально-универсальное, не на индивидуальное и прагматически-утилитар- 
ное, а на специфическое, на то, что открывается в полноте самоосуществления человека во всей его глубине и цельности, на то, что связано с возможностью воплощения личности в ее идеях и идеалах и проявляется в соответствии характера культуры и человека области имманентной трансцендентности, к которой относится индивидуальное и неповторимое душевно-духовное ядро личности. Отсутствие изначальной устремленности к личному благосостоянию и, напротив, ориентация на осуществление идеалов «правды, свободы, общественного благоустройства» (Аанилевский, 1991: 106), на обретение гармонии целостности внутреннего бытия с целостностью внешнего мира, на возможность обретения человеком смысла исторического существования - все это в имплицитном состоянии присутствует в российском культурном коде и сегодня. Нашим современникам по-прежнему присущи: обостренное чувство социальной справедливости, обращенность к вопросам о правде, о новом справедливом обществе, антииндивидуализм, стремление к всеединству. В конце ХХ века исследователи фиксировали, что блок первостепенной важности русской культуры традиционно составляют ценности мира, гостеприимства, уважения к старшим, скромности, патриотизма, святости родной земли и в меньшей степени - богатства и социального лидерства (Каган, 1997: 149).

Однако ценностная система не является константной - она переживает достаточно сложные по содержанию трансформации. Пусть они незаметны во времени в соответствии с малой скоростью протекания этих процессов, тем не менее они есть. Связаны они с развитием в России общества потребления. Несмотря на то что общество потребления в большей степени было характерно для развитых экономик западных стран, в СССР его развитие осуществлялось в тот же послевоенный период достаточно высокими темпами. Существенное отличие тех социально-экономических форм, которые складывались в советском обществе и которые имеют определенное сходство с западным обществом потребления, состоит в ином типе советской экономики, опирающейся не на рыночные экономические структуры, а на плановые. Несмотря на то что в России того времени также присутствовал товарный фетишизм, он существенно корректировался не только внутренними ценностными установками, но и наличием дефицита.

Поэтому, говоря об обществе потребления, мы обычно имели в виду в большей степени западное общество, нежели российское. Но это было ранее. Сегодня же ситуация в экономике России совершенно иная. Товарное изобилие и отсутствие дефицита в полной мере коррелируют с целенаправленной деятельностью СМИ по формированию установок на расширенное потребление. Система кредитования, общественное мнение, реклама целенаправленно формируют у россиян ценность потребления. При этом существенно изменяются функции многих значимых социальных институтов: торговый центр приобретает значение досугового центра, соперничающего по значимости с театром и музеем; сетевые технологии наряду с функцией распространения информации начинают функционировать как активные промоутеры всего, что имеет потребительскую стоимость; образование превращается в сферу предоставления услуг; спорт и медицина становятся чисто коммерческими предприятиями (Lüdtke, 2000).

Мы сегодня являемся свидетелями многих негативных процессов, связанных с доминированием ценностей общества потребления, в котором в процесс потребления вовлекаются и люди - человеческие отношения начинают выступать как отношения потребления, потребляться начинают не только знакомства и приятельские отношения, но и дружба. Причем сам процесс общения часто осуществляется в вещах и через вещи - последние становятся не только их обязательным опосредованием, но 
и заменяющим их знаком (Ильин, 2008ab). Через маркирование социальных отношений посредством обладания вещами определенного класса власть начинает регуляцию процедур упорядочивания общества - обладание вещью определенного бренда позволяет ее обладателю символически означить и место в социальном пространстве, на которое он претендует.

В таком контексте изменяется: концепция вещи (ее функциональность определяется не столько практическими характеристиками, но и символическими, обеспечиваемыми брендом), концепция потребления вещи (вместо стремления продлить потребительские свойства вещи, в том числе, посредством ее ремонта - ориентацию на ее быструю замену другой, более актуальной в социальном плане), стратегия приобретения вещи (формируется такой социальный феномен, как «шопинг» - новая форма досуга, где вещи приобретаются в целях получения психологического удовлетворения). При этом свобода, если интерпретировать данную культурную универсалию не только применительно к целеполаганию, но и к возможности реализации этого принципа, приобретает значение возможности проецирования желания на произведенные товары, инвестирования собственных смыслов и значений в систему дискурса объектов (Костина, 2013аb). При этом создается иллюзорная реальность, смыслы и ценности которой сопряжены только с обладанием. В процесс потребления активно вовлекается не только молодежь, но и дети, для которых быть «как с Рублевки»- устойчивая жизненная установка1.

На первый взгляд можно сделать вывод о том, что ценности Евроатлантической цивилизации в большей степени соответствуют современному экономическому развитию, нежели те принципы, которые отстаивает русская религиозная философия. И в этом смысле наблюдающиеся изменения ценностной парадигмы в России могут рассматриваться как естественные, вызванные трансформациями әкономики, развивающейся в рыночном русле.

Однако это не так. Можно с уверенностью говорить о том, что современная экономическая система России, основанная на принципах свободной конкуренции, и ее социокультурная система, по-прежнему в значительной степени опирающаяся на складывающиеся поколениями ценности, находятся в неполном взаимодействии, а подчас и противоречат друг другу. Экономика, самым непосредственным образом связанная с ценностными основаниями культуры, может развиваться более гармонично при условии ее соответствия внутренним установкам людей, вовлеченных в процесс экономического взаимодействия.

Этот тезис сегодня озвучивают не только отечественные управленцы-ученые, анализирующие экономическое развитие современной России, но и их западные коллеги. Многие из них отмечают кризис неоклассической экономической парадигмы и исчерпание ее эвристического потенциала - в частности, тезис о несоответствии основных постулатов неолиберальной экономической модели содержанию духовного фактора развития культуры как контекста функционирования экономики является лейтмотивом работ академика С. Ю. Глазьева последних двух десятков лет. По мнению С. Ю. Глазьева, которое согласуется с точкой зрения видных западных экономистов Р. Нельсона, С. Винтера, А. Алчиана, неверными оказываются многие основополагающие принципы неолиберальной теории. Среди этих принципов - прежде всего игнорирование значения такого мотива экономической деятельности, как идеологическая направленность поведения и нравственные ограничения (Глазьев, 2010: 56-57).

С. Глазьев выделяет наиболее важные для развития российской экономики основания: необходимость помнить о духовном смысле жизни, заботиться о благе ближ- 
него, общества и Отчизны; восприятие материального благополучия как испытания и ответственности; порядочность в деловых отношениях; необходимость творческого развития человека; необходимость заботы о человеке труда (Глазьев, 2011: 492-500).

Распространение в России потребительского фетишизма и установок, исходящих из «экономики изобилия» (Slater, 1990: 97), становится явным и все более заметным. Оно приводит к стремлению удовлетворить многочисленные, искусственно сформированные потребности, которые воспринимаются в качестве непременного атрибута современного человека, к ориентации на определенные стандарты поведения, имиджи и стереотипы, позволяющие демонстрировать собственное экономическое превосходство или - чаще - имитировать его, к убежденности в относительности шкалы ценностей и готовности ее корректировать в соответствии с изменившимися социальным условиями, к установке на престижное потребление и стремлению соответствовать - хотя бы частично - социальному слою, выступающему в качестве идеального ориентира (Костина, 2013ab).

Конечно, самым важным в этих размышлениях оказывается вопрос о том, что плохого в обществе потребления и чем опасна идея товарного изобилия как условия реализации свободы выбора. Опасность здесь - в замене высоких целей и значимых общественных идеалов на идею расширенного потребления. По-видимому, не случайно в России до сих пор не сложился тот идеал, который мог бы определить вектор ее основного развития и «всем понятный путь ее движения в будущее». Как пишет известный социальный философ И. М. Ильинский, «в 90-е годы власти пытались вместе с учеными создать некий новый вариант национальной идеи. Но из этого ничего не вышло: любой национальный идеал возникает на основе уже существующих философских, политических или религиозных доктрин. Их не было в те времена, нет и сейчас» (Ильинский, 2016: 8).

Но идея потребления не может заменить национальную идею, хотя многие исследователи достаточно оптимистично оценивают перспективы развития общества потребления и человека этого общества. Основные аргументы его апологетиков таковы: во-первых, изобилие товаров рождает конкуренцию, что приводит к повышению качества товаров и услуг, во-вторых, в социальном государстве граждане обладают большей защищенностью, а правительство - большей ответственностью перед обществом, в-третьих, повышается индивидуализация потребления, где возможность выбора активизирует субъектные качества человека, в-четвертых, социальная престижность высокого уровня потребления стимулирует профессиональный рост индивидов и повышение их квалификации, наконец, идентификация на основе потребляемых товаров и услуг смягчает национально-этническое напряжение в обществе, а само потребление начинает выступать как «жизненный стиль» (Miles, 1998).

В то же время очевидно, что общество потребления - это тупиковый путь развития западной цивилизации, живущей в значительной степени за счет «осваиваемых» ей государств и народов, а бездумно уничтожаемые ей ресурсы, большинство из которых является невосполнимыми (Кондратьев, 2005), - это первый шаг к глобальной экологической катастрофе. Причем наибольшей расточительностью отличаются именно представители общества потребления. Согласно данным доклада Совета по защите природных ресурсов, средний американец потребляет «в 5 раз больше любого латиноамериканца, в 10 раз больше китайца и 30 раз больше индуса, выбрасывает в 2 раза больше мусора, тратит в 3 раза больше воды, 4 с лишним раза больше энергии, чем усредненный житель планеты» (В Америке ... : Электронный ресурс). 
Но кроме экологических последствий бездумного потребления, изменяется целеполагание человека; интеллектуальное, нравственное, этическое развитие становится всего лишь условием для повышения конкурентности индивида на рынке труда, целенаправленно понижается уровень образования, так как образованный человек меньше подвержен бездумному потреблению и хуже управляем (Ажеймисон, 2000: Электронный ресурс).

\section{ЗАКАЮЧЕНИЕ}

Каковы же перспективы общества потребления в России? На Западе в экономически развитых странах в настоящее время средний класс начинает разрушаться, а достаточно гомогенная в социальном и экономическом плане структура поляризуется, и это дает основание предположить, что общество потребления как тип общества утрачивает свою значимость. Однако представляется, что в рамках Евроатлантической цивилизации общество потребления является столь неотъемлемой составляющей ее экономики, развивающейся в условиях колоссального перепроизводства товаров, что никакое ухудшение материального положения не заставит человека отказаться от удовольствия потреблять. В России же потребление выполняет еще одну весьма важную функцию - оно становится для человека механизмом сублимации всех недополученных им социальных благ, способом создания иллюзорной реальности стабильности и благополучия, позволяет реализовать зафиксированную в нашей памяти генотипически в период товарного дефицита мечту о возможности удовлетворения практически любых материальных благ.

Аля того чтобы ценность потребления потеряла для граждан России свою привлекательность и была удалена из ценностного ряда, необходимы увеличение внимания государства к каждому человеку, реализация в его интересах многих целей и проектов, имеющих и материальную и социальную природу. Государству должно быть выгодно формировать критически мыслящих граждан, способных к творчеству и созиданию, обладающих патриотическим сознанием, готовых к высокоспециализированной деятельности... Несмотря на то, что они будут не самыми лучшими потребителями.

\section{ПРИМЕЧАНИЕ}

1 Примеров такой беззастенчивой духовной агрессии по отношению к детям - множество. Один из них - скандал 2007 г. вокруг рекламы детских товаров в витринах ЦУМа, где девочка оценивает своих друзей, игрушки и в целом весь мир одной, ставшей мемом, фразой «Кто не в Prada, тот лох!» (Аевочка ЦУМа ..., 2007: Электронный ресурс). Несмотря на то что Торговый дом «ЦУМ» предпочел частично заклеить свои рекламные плакаты, после того как Федеральная антимонопольная служба России решила проверить их на соответствие закону, само появление этой серии плакатов характерно само по себе как знаменующее укоренение в сознании россиян установок на потребление.

\section{СПИСОК АИТЕРАТУРЫ}

В Америке почти половина еды уходит на помойку [Электронный ресурс] // Медицина 2.0. URL: http://www.med2.ru/story.php?id=15103 (дата обращения: 12.09.2016).

Глазьев, С. Ю. (2010) Стратегия опережающего развития России в условиях глобального кризиса. М. : Экономика. 255 с.

Глазьев, С. Ю. (2011) Уроки очередной российской революции: крах либеральной утопии и шанс на «экономическое чудо». М. : Издательский дом «Экономическая газета». 575 с. 
Аанилевский, Н. Я. (1991) Россия и Европа. М.: Книга. 576 с.

Аевочка ЦУМа больше никого не называет лохом (2007) [Электронный ресурс]// BBC.Russian.com. 09 августа. URL: http://news.bbc.co.uk/hi/russian/russia/newsid_6938000/ 6938466.stm (дата обращения: 12.09.2016).

Ажеймисон, Ф. (2000) Постмодернизм и общество потребления [Электронный ресурс] //

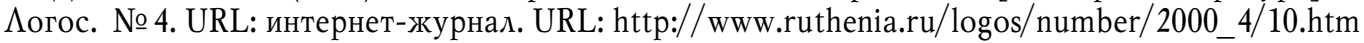
(дата обращения: 12.09.2016).

Ильин, В. И. (2008а) Общество потребления как форма капиталистического развития [Электронный ресурс]// Материалы III Всероссийского социологического конгресса. М. : Институт социологии РАН ; Российское общество социологов. Аиск CD, ISBN 978-6-89697-157-3.

Ильин, В. И. (2008b) Потребление как дискурс. СПб. : Интерсоцис. 446 с.

Каган, М. С. (1997) Философская теория ценности. СПб. : Петрополис. 205 с.

Ильинский, И. М. (2016) О «правильном образовании» и новом министре // Вузовский вестник. № 17 (257). С. 8.

Кондратьев, К. Я. (2005) Современное общество потребления и его экологические ограничения // Энергия. № 10. С. 60-65.

Костина, А. В. (2013а) Массовая культура как феномен постиндустриального общества. М. : URSS. 362 c.

Костина, А. В. (2013b) Современное развитие культуры и современное экономическое развитие: проблема ценностей и духовных оснований. Аоклад [Электронный ресурс]// Культура и глобальные вызовы мирового развития: XIII Международные Аихачевские научные чтения. Секция 4. Экономика и право в контексте мирового культурного развития. URL: http://www. lihachev.ru/pic/site/files/lihcht/2013_Sbornik/2013_Dokladi/2013_Sec4/008_2013_Sec4.pdf (дата обращения: 12.09.2016).

Куренной, В. (2015) Общество потребления [Электронный ресурс]// ПостНаука. 9 февраля. URL: https://postnauka.ru/faq/41327 (дата обращения: 12.09.2016).

Аарошфуко, Ф. де. (1974) Максимы. Паскаль Б. Мысли. Аабрюйер Ж. де. Характеры. М. : Художественная литература. 572 с.

Рапай, К. (2008) Культурный код: Как мы живем, что покупаем и почему : пер. с англ. М. : Альпина Бизнес Букс. 167 с.

Софронов-Антомони, В. (2002) Производство теории потребления // Знание - сила. № 7. C. $18-25$.

Стивенсон, Н. (2002) Глобализация, национальные культуры и культурное гражданство // Глобализация: Контуры XXI века. Реферативный сборник. : в 3 т. / ред. В. П. Малиновский, Ю. И. Игрицкий. М. : ИНИОН РАН. Т. 3. 712 с. С. 5-16.

Baudrillard, J. (1998) The Consumer Society. Myths \& Structures. L., Thousand Oaks, N. Y., Delhi : SAGE Publications. 224 p.

Lüdtke, H. (2000) Konsum und Lebensstile // Rosenkranz, D., Schneider, N. F. Konsum. Soziologische, ökonomische und psychologische Perspektiven. Opladen: Leske und Budrich. 350 p. P. 117-132.

Miles, S. (1998) Consumerism as a Way of Life. London : SAGE Publications. 174 p.

Slater, Ph. E. (1990) The pursuit loneliness American culture at the breaking point. Boston : Beacon Press. 180 p.

Аата поступления: 11.11.2016 2.

\section{CONSUMER SOCIETY AND THE VALUES OF RUSSIAN CIVILIZATION \\ A.V. KOSTINA \\ (MOSCOW UNIVERSITY FOR THE HUMANITIES)}

Contemporary sociocultural reality is changing at so fast a pace that interpreting it becomes difficult. One of the notions that have long been in use, but still remains operational through constant 
rethinking, is that of the 'consumer society'. Three decades ago it was considered characteristic of Western society only, and laden with negative connotations.

The article analyses the system of values of Western consumer society and the extent to which it fits into the economic system of Euroatlantic civilization. At the moment it is clearly understood that consumer society is a universal phenomenon which arises where the market economy takes root and goods are in sustainable abundance. To keep up production rates, an ever increasing consumption of goods and services is needed, and in their turn, advertising and mass media shape a new type of individual - the consumer.

Although consumer society has traditionally been typical for developed economies of the West, in post-WWII USSR it was also developing fast. However, commodity fetishism was sufficiently limited by both internal values and deficiency of goods. The economy of today's Russia is markedly different. The abundance of goods corresponds to the media's efforts to promote the values of increased consumption. Loaning institutions, public opinion and advertising have joined forces to support the values of consumption. However, the sociocultural structure of the Russian society still largely relies on the values of previous generations and do not fully match the principles of free competition - in fact, they often are in direct opposition.

Thus the main goal of the state should be to promote the rise of active and creative citizens, rather than consumers.

Keywords: values; consumer society; Russia; Russian civilization; Russian values; consumer society; Western civilization; Western values; free competition

\section{REFERENCES}

$\mathrm{V}$ Amerike pochti polovina edy ukhodit na pomoiku. Meditsina 2.0 [online] Available at: http://www.med2.ru/story.php?id=15103 (access date: 12.09.2016). (In Russ.)

Glaz'ev, S. Yu. (2010) Strategiia operezhaiushchego razvitiia Rossii v usloviiakb global' nogo krizisa. Moscow, Ekonomika. 255 p. (In Russ.)

Glaz'ev, S. Yu. (2011) Uroki ocherednoi rossiiskoi revoliutsii: krakb liberal' noi utopii i shans na «ekonomicheskoe chudo». Moscow, Izdatel'skii dom «Ekonomicheskaia gazeta». 575 p. (In Russ.)

Danilevskii, N. Ya. (1991) Rossiia i Evropa. Moscow, Kniga. 576 p. (In Russ.)

Devochka TsUMa bol'she nikogo ne nazyvaet lokhom (2007). BBC.Russian.com, 9 August [online] Available at: http://news.bbc.co.uk/hi/russian/russia/newsid_6938000/6938466.stm (access date: 12.09.2016). (In Russ.)

Jameson, F. (2000) Postmodernizm i obshchestvo potrebleniia. Logos, no. 4 [online] Available at: http://www.ruthenia.ru/logos/number/2000_4/10.htm (access date: 12.09.2016). (In Russ.)

Il'in, V. I. (2008a) Obshchestvo potrebleniia kak forma kapitalisticheskogo razvitiia. In: Materialy III Vserossiiskogo sotsiologicheskogo kongressa. Moscow, Institut sotsiologii RAN ; Rossiiskoe obshchestvo sotsiologov, CD, ISBN 978-6-89697-157-3. (In Russ.)

Il'in, V. I. (2008b) Potreblenie kak diskurs. St. Petersburg, Intersotsis. 446 p. (In Russ.)

Kagan, M. S. (1997) Filosofskaia teoriia tsennosti. St. Petersberg, Petropolis. 205 p. (In Russ.)

Ilinskiy, I. M. (2016) O «pravil'nom obrazovanii» i novom ministre». Vuzovskii vestnik, no. 17 (257), pp. 8. (In Russ.)

Kondrat'ev, K. Ya. (2005) Sovremennoe obshchestvo potrebleniia i ego ekologicheskie ogranicheniia. Energiia, no. 10, pp. 60-65. (In Russ.)

Kostina, A. V. (2013a) Massovaia kul'tura kak fenomen postindustrial'nogo obshchestva. Moscow, URSS. 362 p. (In Russ.)

Kostina, A. V. (2013b) Covremennoe razvitie kul'tury i sovremennoe ekonomicheskoe razvitie: problema tsennostei i dukhovnykh osnovanii. Doklad. Kul' tura i global' nye vyzovy mirovogo razvitiia: XIII Mezbdunarodnye Likhachevskie nauchnye chteniia. Sektsiia 4. Ekonomika i pravo v kontekste mirovogo kul' turnogo razvitiia [online] Available at: http://www.lihachev.ru/pic/site/files/lihcht/ 2013_Sbornik/2013_Dokladi/2013_Sec4/008_2013_Sec4.pdf (access date: 12.09.2016). (In Russ.)

Kurennoi, V. (2015) Obshchestvo potrebleniia. PostNauka, 9 February [online] Available at: https:// postnauka.ru/faq/41327 (access date: 12.09.2016). (In Russ.) 
La Rochefoucauld, F. de. (1974) Maksimy. Pascal B. Mysli. Labruyere J. de. Kbaraktery. Moscow, Khudozhestvennaia literatura. 572 p. (In Russ.)

Rapaille, C. (2008) Kul'turnyi kod: Kak my zhivem, cbto pokupaem i pochemu. Moscow, Al'pina Biznes Books. 167 p. (In Russ.)

Sofronov-Antomoni, V. (2002) Proizvodstvo teorii potrebleniia. Znanie - sila, no. 7, pp. 18-25. (In Russ.)

Stevenson, N. (2002) Globalizatsiia, natsional'nye kul'tury i kul'turnoe grazhdanstvo. In: Globalizatsiia: Kontury XXI veka. Referativnyi sbornik: in 3 vols., ed. by V. P. Malinovskii and Yu. I. Igritskii. Moscow, INION RAN. Vol. 3. 712 p. Pp. 5-16. (In Russ.)

Baudrillard, J. (1998) The Consumer Society. Myths \& Structures. L., Thousand Oaks, N. Y., Delhi, SAGE Publications. 224 p.

Lüdtke, H. (2000) Konsum und Lebensstile. In: Rosenkranz, D., Schneider, N. F. Konsum. Soziologische, ökonomische und psychologische Perspektiven. Opladen: Leske und Budrich. 350 p. Pp. 117-132.

Miles, S. (1998) Consumerism as a Way of Life. London, SAGE Publications. 174 p.

Slater, Ph. E. (1990) The pursuit loneliness American culture at the breaking point. Boston, Beacon Press. 180 p.

Submission date: 11.11.2016.

Костина Анна Владимировна - доктор философских наук, доктор культурологии, професcop, декан факультета культуры и искусства, заведующий кафедрой философии, культурологии и политологии Московского гуманитарного университета, действительный член Международной академии наук (IAS, г. Инсбрук, Австрия). Адрес: 111395, Россия, г. Москва, ул. Юности, А. 5. Тел.: +7 (495) 374-61-81. Эл. адрес: Anna_Kostina@inbox.ru

Kostina Anna Vladimirovna, Doctor of Philosophy, Doctor of Culturology, Professor and Dean, Faculty of Culture and Arts; Chair, Department of Philosophy, Culturology and Politology, Moscow University for Humanities; Full member; International Academy of Sciences (IAS, Innsbruck, Austria). Postal address: 5 Yunosti St., Moscow, Russian Federation 111395. Tel.: +7 (495) 374-61-81. Email: Anna_Kostina@inbox.ru 